\title{
Feral rabbit populations in a peri-urban area: insights about invasion dynamics and potential management strategies
}

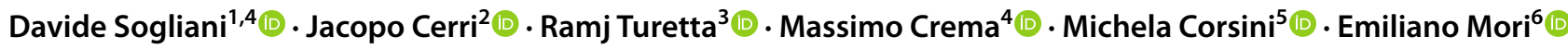

Received: 7 August 2020 / Revised: 25 May 2021 / Accepted: 28 May 2021 / Published online: 2 June 2021

(c) The Author(s) 2021

\begin{abstract}
Where introduced, the European rabbit Oryctolagus cuniculus is considered among the most destructive and invasive species. To date, research focused mostly on populations of wild rabbit, whereas little is known on feral domestic rabbit populations. In this work, we reported the establishment of two self-sustaining populations of feral rabbits in Italy. Direct observations were conducted to assess rabbit range expansion and population increase over time. We also evaluated prey-predator interactions between rabbits and native red foxes Vulpes vulpes, by means of camera trapping and the analysis of fox scats. Moreover, we also assessed the social perception towards feral rabbits and the acceptability of various management options through the administration of a structured questionnaire to park visitors. Rabbit populations increased between 2018 and 2019, as well as the size of the invaded range. Rabbits are predated by foxes, but they seem to have adapted their activity rhythms to minimize the risk of predation, becoming diurnal. Park visitors loved rabbits and deemed them to be a positive presence in the park, which deserve to live there. Surgical sterilization of rabbits was the only management option which was partially supported. Feral domestic rabbits, albeit a neglected species in invasion biology, can become extremely successful invaders of urban green areas: in $<5$ years, rabbits were able to colonize our study area and become a food resource for native predators and also an iconic species. These three points raise concerns about the potential impacts of invasive feral rabbits in European urban green areas and call for further research in this direction.
\end{abstract}

Keywords Alien species · Invasive species establishment · Feral rabbits · Oryctolagus cuniculus domesticus $\cdot$ Predatorprey interactions $\cdot$ Socio-ecological model

Davide Sogliani

davide.sogliani@gmail.com

1 Department of Biology and Biotechnology, University of Pavia, via A. Ferrata, 9, 27100 Pavia, Italy

2 Department of Life Sciences and Systems Biology, University of Turin, via Accademia Albertina, 13, 10123 Torino, Italy

3 Department of Chemical and Geological Sciences, University of Modena and Reggio Emilia, via G. Campi, 103, 41125 Modena, Italy

4 WWF Mantovano, Operative Unit of Mantova, strada Formigosa, 36, 46100 Mantova, Italy

5 Centre of New Technologies, University of Warsaw, ul. S. Banacha, 2c, 02-097 Warsaw, Poland

6 Consiglio Nazionale Delle Ricerche, Istituto Di Ricerca Sugli Ecosistemi Terrestri, Via Madonna del Piano, 10, 50019 Sesto Fiorentino, Florence, Italy

\section{Introduction}

Domesticated animals establishing viable populations in the wild after their escape or release (i.e., a process known as "feralization": Daniels and Bekoff 1989) can become major biological invaders and pests. Examples include feral hogs (Battocchio et al. 2017), dogs (Young et al. 2011), horses (Nimmo and Miller 2007), and cattle (Micol and Jouventin 1995). Compared to wild invasive species, feral species are usually harder to manage, because they are often iconic and well-known to the general public, due to their domestic nature (Nimmo and Miller 2007; Young et al. 2011), because sometimes their identification is difficult (Randi 2007) and because their legal status is often ambiguous (Trouwborst 2014).

The European rabbit can become invasive both in its wild (Oryctolagus cuniculus) and in its domesticated form $(O$. cuniculus domesticus). The wild European rabbit is a "conservation paradox" (Lees and Bell 2008): although the species is among the most impacting invasive alien species in 
some areas of the world (Pech et al. 1992; Courchamp et al. 1999, 2001; Pimentel et al. 2001; Katona et al. 2004; Cooke et al. 2008; Delibes-Mateos et al. 2008a, 2018; Flux 2008; Lees and Bell 2008; Ferreira 2012; Papadopoulos et al. 2017), at the same time, it is classified as "Endangered" by the IUCN due to a long-term population decline in its native range (https://www.iucnredlist.org/species/41291/45189779; Villafuerte and Delibes-Mateos 2019). The European rabbit can also become invasive through the feralization of domestic individuals. Feral rabbits generally become invasive in urban green areas and periurban parks, where their populations can reach densities comparable to those of wild rabbits, with potentially similar negative consequences for the environment, native wildlife, and human health (Watson 1961; Retfalvi 1970; Vastrade 1986, 1987; Mori 2010).

The number of studies about the ecology and impacts of feral domestic rabbits is much lower than that of studies about invasive European wild rabbits. We believe that this knowledge gap deserves to be filled because, as rabbits have become a major pet over the last few decades (Meredith and Brigitte 2014), their incursion into natural areas is likely to rise, and managing their populations will become increasingly important and challenging. In this work, we document the status of two populations of domestic rabbits that have become feral and well-established in the Mincio Park (Northern Italy). We evaluated whether feral rabbits have (i) increased in number and spread around their introduction site, (ii) altered food webs by becoming a prey for native predators, and (iii) become an iconic species.

\section{Material and methods}

\section{Study site}

Our study area is located around the city of Mantova, in the Mincio Park (Lombardy, Northern Italy), within or at the border of the Special Protection Area "Valli del Mincio." The protected area is divided into two different areas, characterized by two different populations of feral domestic rabbits. Area 1 is on the bank of Mantuan Upper Lake, and Area 2 is on the bank of Mantuan Middle Lake, each one hosting a population of feral rabbits (Fig. 1). Rabbits have been present since 2016 , following multiple releases from captivity. We found evidence that various rabbits were released by residents, by a farmer and by the staff of a local bar to attract customers (anonymous, personal communication).

The study area is characterized by heterogeneous vegetation, typical of an Italian lowland habitat with woodlands (mainly Morus nigra, Fraxinus excelsior, Salix spp., Robinia pseudoacacia, Populus nigra, Populus alba, Acer campestre, Ulmus minor, Celtis australis, Quercus robur, Carpinus betulus, Prunus avium, Juglans regia, Alnus glutinosa, Platano hybrida, Tilia platyphyllos), meadows (mainly Lolium spp., Bromus spp., Parietaria officinalis, Taraxacum officinale, Trifolium pratense, Stellaria media, Plantago lanceolata, Lamium purpureum, Equisetum arvense, Cirsium vulgare, Phragmites australis, Typha spp.) and scrublands (mainly Rubus ulmifolius, Cornus sanguinea, Sambucus nigra, Corylus avellana, Hedera helix, Phytolacca americana, Euonymus europaeus, Crataegus spp.). Orchards, fallows, and human settlements, including a railway station, are also present. The average annual rainfall is $795.6 \mathrm{~mm}$, with rare snowfalls and the average annual temperature is $13.7^{\circ} \mathrm{C}$ (the average temperature in January is $3.2{ }^{\circ} \mathrm{C}$; the average temperature in July is $22.1{ }^{\circ} \mathrm{C}$; World Weather Online).

\section{Data collection and analysis}

\section{Population size and range expansion}

Between March 2018 and March 2020, we performed $144 \mathrm{~h}$ of direct (i.e., through naked eyes and binocular $10 \times$ Olympus $10 \times 42$ EXPS I) and opportunistic observations carried out while walking, or driving where possible, at the two study areas, along a fixed pathway of $7.5 \mathrm{~km}$ repeated at each survey. We looked for rabbits, signs of their presence (e.g., diggings, faecal pellets, burrows), and their predators (including scats: ESM_1; Dodaro et al. 2019). We identified individual rabbits by physical characteristics (e.g., coat colour, hair length, ear morphology, spot patterns, morphological features; Whitman 2004; ESM_1) and, following this protocol, we added " +1 " to the count for each time a new individual was identified. The count of individuals was performed over a three-month period both at the start (March-June 2018) and at the end (October-December 2019) of our monitoring activity. This method may underestimate rabbit abundance due to the presence of few individuals with very similar or identical phenotype. Juveniles younger than about 60 days were not counted, because of the potential high juvenile mortality and to avoid double counts once they had become adults.

We used Minimum Convex Polygon (MCP) to estimate individuals' range. MCP is a standardized and easily applicable internationally accepted approach to estimate home ranges in free-ranging populations. Most importantly, MCPs are widely used when presence-only data are available as spatial information of individuals' occurrence (Burgman and Fox 2003).

We geolocated observations/records with a GPS (Garmin eTrex 20), to assess rabbit expansion in the two areas; then, we produced two distribution maps (Fig. 1), based on the 95\% MCP (Burgman and Fox 2003).

The MCP draws the smallest polygon around records with all interior angles lower than $180^{\circ}$. The MCP was computed with all our georeferenced occurrences of rabbits (ESM_5). Shortcomings of MCP (Burgman and Fox 2003) have been 


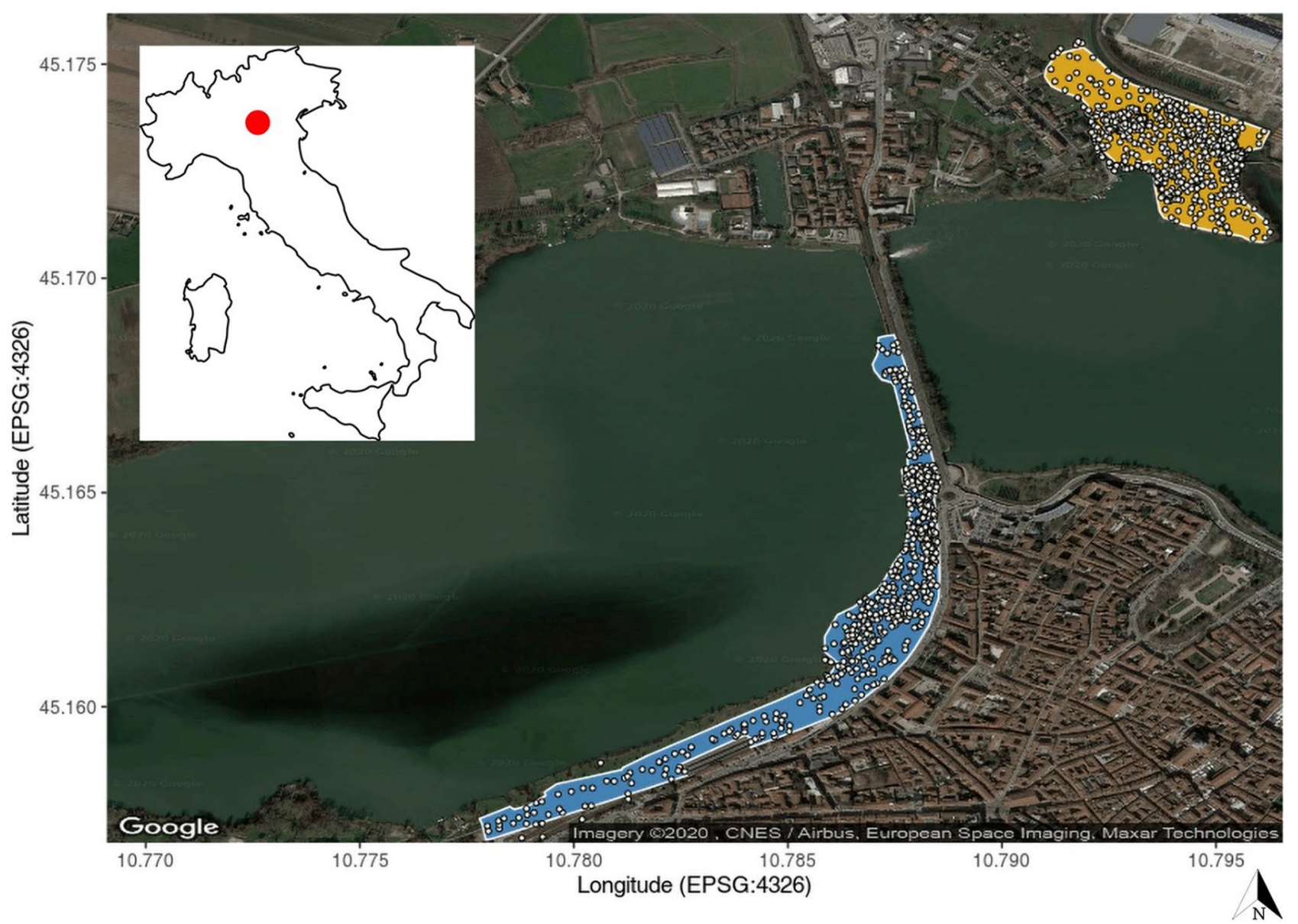

Fig. 1 Overview of the study site. Area 1 and Area 2 are shown respectively in blue and yellow. GPS coordinates are visualised as white spots

mitigated by discarding the peripheral $5 \%$ of records, i.e., the extreme locations. MCP was calculated through the opensource software QGIS (QGIS Development Team 2019, v. 3.10, "A Coruña"). Specifically, observed data points were first uploaded in the software and then transformed in the map projection of the study area (here, specifically: "Monte Mario/Italy zone 1, EPSG: 3003"). MCPs were calculated by site and year using the function "Minimum Boundary Geometry" in the "Processing toolbox," by selecting the geometry type "Convex Hull." Because our study sites included water bodies, MCP was further corrected by excluding the layers (here identified as "polygons") containing water bodies. Polygons specifying the location of water bodies were drawn using "Google Satellite" and "OSM standard" as basic maps, which are available in the Plugin "QuickMap Services" of the software. At this point, the exclusion of water bodies from the original MCP was obtained through the function "difference" in "Geoprocessing tools." Finally, population densities were estimated by dividing the total number of individuals counted between October and December 2019 with the corrected MCP value described above.

\section{Camera-trapping survey and temporal overlap}

Between December 2019 and March 2020, four camera traps (CamPark T45, $n=1$; Apeman Trail Cam H70, $n=3$ ) were placed in Area 2 at a height of $\sim 30-60 \mathrm{~cm}$ above ground level, to estimate activity patterns of rabbits and foxes and to record predation events on rabbits. Cameras were locked with chains on the closest tree to predetermined random points selected through QGIS (QGIS Development Team 2019) within a regular grid covering Area 2. No camera trap was placed in Area 1 which was highly frequented by humans, to avoid thefts and privacy issues.

Cameras were activated $24 \mathrm{~h} /$ day to take three pictures each time they were triggered (with 1-min delay between triggers) and, owing to their remote positioning, no people or vehicles were filmed, thereby respecting privacy. Red foxes and rabbits show a strong predator-prey relationship, and foxes are reported to limit rabbit populations in Southern Europe (Delibes-Mateos et al. 2008b; Fernandez-de-Simon et al. 2015). We used the software R 3.6.2 (R Core Team 2019), package overlap (Meredith and Ridout 2018) to assess 
patterns of activity overlap between the red fox, i.e., the most widespread carnivore in our study site, and the domestic rabbit. Other potential predators of wild rabbits present in the study area includes the stone marten Martes foina as well as free-ranging domestic cats Felis catus and unleashed dogs Canis familiaris. Anecdotal information reports that both feral cats and unleashed dogs have killed some rabbits in our study area. However, we discarded all these predators from analyses as records from camera traps were numerically limited (stone marten, $n=6$; feral cat, $n=3$; unleashed dog, $n=8$ ) to provide reliable results (Lashley et al. 2018). We deleted from our dataset all photographs of the same species occurred at the same site in $<30 \mathrm{~min}$ to reduce pseudoreplication (Linkie and Ridout 2011). We estimated the overlap coefficient ( $\Delta_{1}$ estimator) among temporal activity patterns of the two species in the same study area, which may range between 0 (i.e., 0\% overlap) and 1 (i.e., $100 \%$ total overlap: Linkie and Ridout 2011; Meredith and Ridout 2018). We used the " $\Delta_{1}$ estimator," as one of the species of the pairwise comparison provided us with less than 75 records; whereas when both species involved in the overlap analysis include more than 75 records, the " $\Delta_{4}$ estimator" is used (Linkie and Ridout 2011; Meredith and Ridout 2018). The $95 \%$ confidence intervals (95\% CIs) of the coefficient of overlap were calculated through 10,000 bootstrap replicates (Mori et al. 2020). Overlap was categorized as "low" with $\Delta<0.50$, "moderate" with $0.50<\Delta<0.75$, and "high" with $\Delta>0.75$ (Monterroso et al. 2014).

\section{Scat analysis}

Despite potential limitations (Reynolds and Aebischer 1991), the morphological analysis of food remains in scats is still one of the most reliable and cost-efficient methods to assess the diet of the red fox (Sogliani and Mori 2019; Ferretti et al. 2021).

While walking on the transects, we collected all detected scats of red foxes and we stored them in plastic bags labelled with dates and locations. Scats were preserved in a $-20{ }^{\circ} \mathrm{C}$ freezer before analyses.

For the analysis, scats were dehydrated and sterilized with a heater at $60^{\circ} \mathrm{C}$ for $3 \mathrm{~h}$ and $15 \mathrm{~min}$, to avoid transmission of potential zoonoses through aerosol. Then, undigested materials (i.e., bones and hairs) were separated in water solution, and kept in labelled tubes (cf. Sogliani and Mori 2019; Ferretti et al. 2021). Hairs of different species show differences both in the macroscopical and in the microscopical structure. General colour was analysed by eye, whereas cuticula and medulla were analysed at the binocular microscope (B-192 s Optika $600 \times)$. In detail, to analyse the cuticula, the hair was placed on a glass slide, on a layer of transparent nail polish. After the slide was completely dry, the hair was removed with steel tweezers. Then, the mould was observed at the microscope and compared with specific atlases (Faliu et al. 1980; Teerink 1991) and the local reference collection of the Department of Life Sciences of the University of Siena (Italy). Conversely, to analyse the medullar structure, the hair was cross-sectioned and wet with cedar oil at the section level (Mori et al. 2016). The prepared slide was observed under the microscope, so to compare the structure of the medulla with the reference collection

\section{Questionnaire survey}

Between December 2019 and April 2020, we also administered on-site $(n=151)$ and online $(n=139)$ questionnaires, to measure whether and how visitors perceived the presence of rabbits in the park. On-site questionnaires were administered to a sample of visitors, recruited during transects for population monitoring. It is worth emphasising that our sample was not drawn at random from some sampling frame, and it was therefore a convenience sample, obtained by recruiting visitors who were intercepted by researchers on the field. We did not record the response rate, as we did not have a definite sampling frame, but rather people who were encountered at the park. Online questionnaires were implemented on Google Forms. A link to the questionnaire was posted on some Facebook groups about the park, asking group members to complete the questionnaire. Both questionnaires were confidential, and they took about 10-15 $\mathrm{min}$ to be completed.

Questionnaires measured beliefs about the potential positive (increased environmental quality of the park, increased aesthetic quality of the park, increased number of repeated visits, increased number of visitors, increased visitors' satisfaction), and negative impacts (transmission of zoonoses, transmission of diseases to native wildlife, vegetation damaging, disturbance of other wildlife) of rabbits in the park, emotions towards rabbits, existence beliefs about rabbit presence in the park, interactions between visitors and rabbits (observation, touching, feeding), and visitor's preferences for various management options concerning rabbits: shooting, euthanasia after trapping, sterilization and maintenance in captivity, sterilization and adoption by private citizens, sterilization, and release in the park. We also collected baseline information about park usage and visitor's characteristics.

Beliefs towards the impacts of rabbits, discrete emotions, and beliefs about the existence value of rabbit presence in the park were measured by asking respondents to rate their agreement with a series of statements on a 7-point bipolar scale (Vaske 2008), ranging from "Strongly disagree" $(-3)$ to "Strongly agree" $(+3)$. Interactions between visitors and rabbits were measured with on an ordered scale with 3 options, corresponding to the frequency of each interaction ("Never," "Regular," "Always"). Visitors' preferences for the management of rabbits in the park were measured by asking 
them to rate the level of acceptability of the various options, on a 5-point unipolar scale, ranging from "Unacceptable" (1) to "Acceptable" (5). A complete overview of the various statements contained in the questionnaire is available in the Supplementary Material.

We grouped the two beliefs about the positive and negative impacts of rabbits, into a single construct with two latent variables, expressing the overall perception of rabbits, through Confirmatory Factor Analysis, and we measured the reliability of this construct through Cronbach's alpha. We also averaged disgust and fear (negative emotions) and happiness and interest towards rabbit (positive emotions). The overall evaluation of respondents' perception of rabbit was made based on descriptive statistics of the raw and estimated scores. When grouping multiple questions into a single psychometric construct, the reliability and validity of the underlying model should be tested through the Cronbach's alpha and also by inspecting fitness indexes of the confirmatory factor analysis. Further explanations about latent variable models and measurement reliability are available in Beaujean (2014) as also Tavakol and Dennick (2011). Latent variable models were fitted with the package lavaan (Oberski 2014), and the Cronbach's alpha was calculated with the package psych (Revelle 2019). A comprehensive overview about survey structure is available in the Supplementary Material (ESM_2, 3, 4).

\section{Results}

\section{Population size and range expansion}

At the start of our monitoring activity, we observed 27 rabbits in Area 1, and 48 in Area 2. At the end of December 2019, we counted approximately 56 and 61 rabbits for Area 1 and 2, respectively. We also recorded a low escape distance, always less than $4.5 \mathrm{~m}$.

In Area 1, the range of feral rabbits increased from 4.7 ha in 2018 to 17.1 ha in 2019. In Area 2, the range increased from 5.1 ha in 2018 to 9.8 ha in 2019. At the end of our monitoring activity, rabbits were present at a density of 3.3 individuals/ha for Area 1 and 6.2 individuals/ha for Area 2.

\section{Rabbits and native red foxes}

We detected a very low overlap of activity rhythms $\left(\Delta_{1}=0.20\right)$ between the red fox (253 occurrences) and the domestic rabbit (33 occurrences): the former was mostly nocturnal with a limited diurnal activity; the latter was diurnal (Fig. 2).

We also detected the presence of rabbit remains in all analysed red fox scats $(n=5)$, and also around fox dens. Camera traps (total camera-trap days $=300$ ) in and around Area 2 detected red foxes carrying predated rabbits four times (ESM_1).

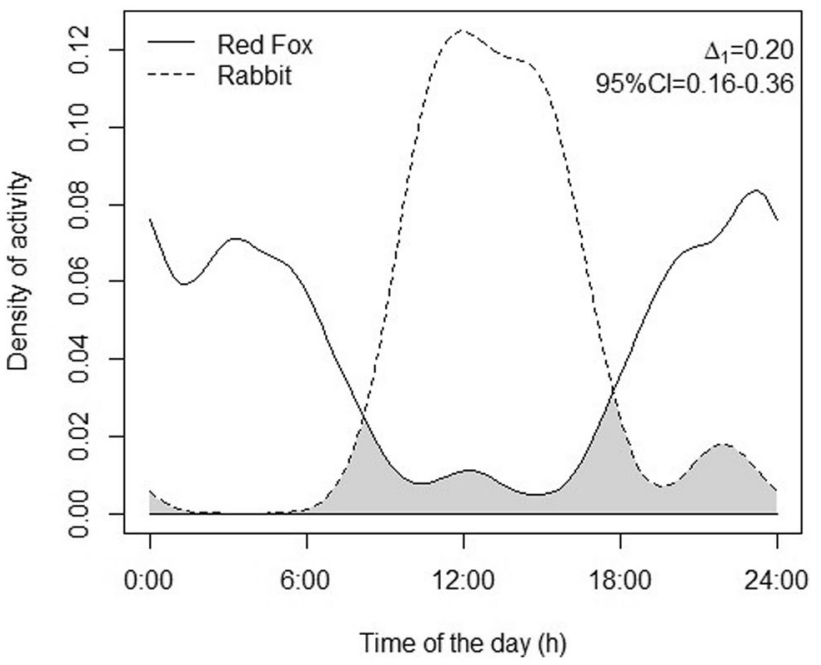

Fig. 2 Temporal activity overlap between the red fox and the domestic rabbit. The overlap coefficient is the shaded area under the two density estimates and is reported, along with the $95 \% \mathrm{CI}$, at the topright corner of the graph

\section{Perception of rabbits by park visitors}

Confirmatory factor analysis revealed that respondents had reliable (Cronbach's alpha, positive impacts $=0.90$; Cronbach's alpha, negative impacts $=0.88$, see Tavakol and Dennick, 2011, for an overview of the index) and valid $(\mathrm{CFI}=0.97, \mathrm{SRMR}=0.03, \mathrm{TLI}=0.95$, see Beaujean 2014 for fitness indexes in CFA) beliefs about the potential impacts of rabbits in the park. Respondents were more uncertain about negative impacts.

Respondents also showed clearly positive emotions (joy and interest, median $\pm \mathrm{sd}=2.00 \pm 1.79$, Cronbach's alpha $=0.91$; disgust and fear, median $\pm \mathrm{sd}=-2.50 \pm 1.39$, Cronbach's alpha $=0.81$ ) at the idea of encountering rabbits while visiting the park. They also had stable existence values governing their acceptance of rabbit presence, believing that maintaining rabbits in the park would be important for the future generations and that rabbit presence is important per se, even if people do not come into contact with them (median $\pm \mathrm{sd}=1.5 \pm 1.65$, Cronbach's alpha $=0.75$ ). Respondents also believed that rabbits possess the right to live in the park (median $\pm \mathrm{sd}=4 \pm 1.26$ ).

Rabbits were a common experience for visitors. Overall, $78.3 \%$ of respondents were aware of rabbit presence at the park: of these, $96.0 \%$ declared to have encountered, $12.0 \%$ to have touched, and $18.0 \%$ to have fed a rabbit at least once, while visiting the park. Most respondents opposed the idea of removing rabbits from the park $(64.8 \%)$, and there was a widespread disagreement with the idea of doing so by shooting them (84.5\%). Capturing, surgically sterilizing and releasing rabbits in the park was the only option that received a certain support from 
respondents $(57.2 \%)$. Overall, respondents were interested towards further educational initiatives about invasive alien species (ESM_2).

\section{Discussion}

In this study, we reported the first case of establishment of free-ranging domestic rabbit populations in Italy, which is also one of the few available studies in the scientific literature (e.g., Watson 1961; Retfalvi 1970; Vastrade 1986, 1987).

Our findings indicate that released domestic rabbits produced two self-sustaining populations. Even if recorded over a very short time period, the locally observed population increase was probably related to a combination of the high reproductive potential of the species with its ecological flexibility and with the absence of competing lagomorphs in the periurban parks. Currently, the status of our invasive rabbit population can be considered as a stage IVb ("established and localized populations composed by a high density of individuals," Colautti and MacIsaac 2004). In $<5$ years, rabbits reached very high densities in the Mincio park and between 2018 and 2019, rabbit abundance (i.e., the number of records we obtained in our transects) increased by 107\% in Area 1 and 27\% in Area 2, where some foxes were also detected through camera-trapping, and where predation towards rabbits was recorded. Also, the range where rabbits were detected increased by almost 364\% Area 1 and $200 \%$ Area 2, over these 2 years. The extent to which rabbits increased their presence, in such of a short time span, calls for two reflections. The first one is about the tremendous demographic potential of feral domestic rabbits, which seems to be comparable to that of invasive wild European rabbits (e.g., Zenger et al. 2003) in their introduction range. The second one is about the capacity of feral rabbits to disperse from around of their introduction site. Although rabbits at the moment are quite localized, they are rapidly spreading in the Mincio park and their range is likely to increase in the near future, with rabbits using both the riparian vegetation of the Mincio River as an ecological corridor (Bencharif 2010) and the railway of Area 1 (DelibesMateos et al. 2018). These two aspects need further research, because the expansion of invasive feral rabbits around the study area might produce negative impacts within the riparian ecosystem. These impacts could be due to burrowing of the dens (Dalland and Carter 1998; Cooke 2012) and effects on the native European hare Lepus europaeus through disease transmission (Barlow et al. 2014; Velarde et al. 2017). We believe that capture-recapture studies, based on a regular grid of traps and adopting the robust design, might be an effective method to estimate the demographic parameters of rabbit populations, as well as to monitor their spatial expansion (cf. Daly 1980). Studies adopting this approach would also correctly estimate the size of our expanding rabbit population, by accounting for undetected individuals, and therefore, they would compensate for some underestimation in our approach, which was based on point counts.

Our findings also provide multiple evidence for preypredator interactions between invasive rabbits and native predators, such as the red fox. Foxes prey upon rabbits, but data about activity rhythms indicate that rabbits might also adapt their behaviour to limit fox predation. Although rabbits are known as crepuscular or nocturnal species (Olivas et al. 2013; Díez Valle et al. 2013), those in our study area were mainly diurnal. This produced a slight overlap in the activity rhythm of foxes, much lower than previous studies performed on wild rabbits (Díaz-Ruiz et al. 2016; Caravaggi et al. 2018). Considering the study area is regularly frequented by visitors during the daytime, this behaviour could be a recent adaptation that limits predation by foxes, whose nocturnal activity is consistent with the risk allocation hypothesis (Suselbeek et al. 2014). As rabbits are expanding throughout the Mincio park, it would be interesting to see if similar activity patterns would hold true in areas with lower human presence.

The fact that rabbits are preyed by foxes also calls for further research about the consequence of this prey-predator interaction over invaded ecosystems. Invasive alien species can sometimes outcompete native species through indirect competition, by maintaining unnatural high densities of native predators (Courchamp et al. 1999, 2001; Norbury 2001; Lees and Bell 2008). In Italy, this was reported between invasive Eastern cottontails Sylvilagus floridanus and native European hares (Cerri and Bertolino 2017), through a competition mediated by native foxes. As feral rabbits are likely to expand around the study area in the near future, due to the absence of any managed population control, future studies should explore whether they will indirectly compete with other lagomorph species.

Finally, our study offers some important insights into human dimensions of feral domestic rabbits in (peri-)urban parks as well as optimum strategies to limit their populations. Data from our structured questionnaire indicate that feral rabbits at an urban park can become valued by visitors within a few years, and extremely short time period. This study area seems to be characterized by important human rabbit interactions. A relatively high proportion of respondents reported to have fed or touched a rabbit, while visiting the park, and rabbits showed short escape distances when approached. The study area seems to be characterized by important human-rabbit interactions. Therefore, not surprisingly, a vast majority of respondents supported rabbit presence, had stable beliefs about their positive impacts over the quality of the Mincio park, and had positive emotions connected with rabbit presence. Even less surprisingly, our respondents opposed intrusive management options that 
risked harm to rabbits and only partially endorsed surgical sterilization of rabbits, followed by their release in the park. Overall, our findings indicate that removing rabbits from the study area might be an unfeasible management option and likely to fuel long-term social conflicts (Crowley et al. 2017) which can undermine rabbit management in the short term. However, considering that some respondents supported the surgical sterilization of rabbits and that about $80 \%$ of them also showed some interest in learning about invasive alien species, we believe that managing rabbits in the study area through a well-communicated sterilization campaign, coupled with rabbit release in the park might be effective to counteract rabbit expansion in the Mincio park. Communication campaigns were found to be effective at increasing human acceptance of invasive alien species management, at least when people are interested about biological invasions (Sol Hart and Larson 2014), and we believe that this might be the case for our study area. To date, control of invasive mammal species throughout sterilization has been achieved only on islands or at urban parks (Da Silva et al. 2010; Scapin et al. 2019), and our case study might contribute to broaden evidence about the effectiveness of nonlethal management of invasive alien species.

\section{Conclusions}

To the best of our knowledge, this study is the first to provide a comprehensive assessment of the invasive status of a population of invasive feral domestic rabbits at an urban area. By exploring the spatial and numerical expansion of rabbit population, their interaction with native predators, and their perception by park visitors, we showed that feral rabbits can become successful invaders or urban green areas, in extremely short times scales. In these contexts, they can affect native predators and their management is likely to be constrained by their social acceptance.

As domestic rabbits became a widespread pet in Europe over the last few decades, the number of abandoned or escaped rabbits is likely to increase, especially at urban parks, as it was observed for other invasive mammals (e.g., squirrels, Bertolino 2009). Therefore, we believe that future studies should now explore their ecological impacts at their introduction sites, and on optimal management strategies, which might considerably differ from those used for invasive wildlife.

Supplementary Information The online version contains supplementary material available at https://doi.org/10.1007/s10344-021-01505-2.

Acknowledgements We are grateful to two anonymous volunteers that helped us with the data collection and to Dr. Bruno Bedonni who helped us in the identification of the botanical species mentioned in the
"Study site" section. We would like also to thank Dr. Ilaria Adami and Dr. Federico Grilli for assistance with figure preparation. We thank an anonymous reviewer and Dr. David Eldridge for their careful reading of our manuscript and their insightful comments.

Author contribution DS: Conception and design of the study, data collection and analysis, interpretation of results, manuscript writing; EM: Conception and design of the study, data analysis, interpretation of results, manuscript drafting; RT, MCr: Data collection, interpretation of results; JC: Conception and design of the study, major contribution in questionnaire design and data analysis, interpretation of results, manuscript writing; MCo: Data analysis, interpretation of results. All authors read and approved the final manuscript.

Funding Open access funding provided by Università degli Studi di Pavia within the CRUI-CARE Agreement.

Availability of data and material All data generated or analysed during this study are included in its supplementary information files.

Code availability Code of the current study is available from the corresponding author.

\section{Declarations}

Ethics approval This article does not contain any studies with animals performed by any of the authors.

Informed consent Informed consent was obtained from all individual participants included in the study.

Conflict of interest The authors declare no competing interests.

Open Access This article is licensed under a Creative Commons Attribution 4.0 International License, which permits use, sharing, adaptation, distribution and reproduction in any medium or format, as long as you give appropriate credit to the original author(s) and the source, provide a link to the Creative Commons licence, and indicate if changes were made. The images or other third party material in this article are included in the article's Creative Commons licence, unless indicated otherwise in a credit line to the material. If material is not included in the article's Creative Commons licence and your intended use is not permitted by statutory regulation or exceeds the permitted use, you will need to obtain permission directly from the copyright holder. To view a copy of this licence, visit http://creativecommons.org/licenses/by/4.0/.

\section{References}

Barlow A, Lawrence K, Everest D, Dastjerdi A, Finnegan C, Steinbach F (2014) Confirmation of myxomatosis in a European brown hare in Great Britain: Myxomatosis. Vet Rec 175:75-76. https://doi. org/10.1136/vr.g4621

Battocchio D, Iacolina L, Canu A, Mori E (2017) How much does it cost to look like a pig in a wild boar group? Behav Processes 138:123-126. https://doi.org/10.1016/j.beproc.2017.03.001

Beaujean AA (2014) Latent variable modeling using R: A step-by-step guide. Routledge/taylor \& Francis Group. https://doi.org/10.4324/ 9781315869780

Bencharif ST (2010) Climate Change and connectivity: are corridors the solution? Dissertation. Queen's University Kingston, Ontario, Canada 
Bertolino S (2009) Animal trade and non-indigenous species introduction: the world-wide spread of squirrels. Divers Distrib 15:701708. https://doi.org/10.1111/j.1472-4642.2009.00574.x

Burgman MA, Fox JC (2003) Bias in species range estimates from minimum convex polygons: implications for conservation and options for improved planning. Anim Conserv 6:19-28. https:// doi.org/10.1017/S1367943003003044

Caravaggi A, Gatta M, Vallely M, Hogg K, Freeman M, Fadaei E, Dick JTA, Montgomery WI, Reid N, Tosh DG (2018) Seasonal and predator-prey effects on circadian activity of free-ranging mammals revealed by camera traps. PeerJ 6:e5827. https://doi.org/10. 7717/peerj.5827

Cerri J, Ferretti M, Bertolino S (2017) Rabbits killing hares: an invasive mammal modifies native predator-prey dynamics. Anim Conserv 20:511-519. https://doi.org/10.1111/acv.12343

Colautti RI, MacIsaac HJ (2004) A neutral terminology to define 'invasive' species. Divers Distrib 10:135-141. https://doi.org/10. 1111/j.1366-9516.2004.00061.x

Cooke BD (2012) Rabbits: manageable environmental pests or participants in new Australian ecosystems? Wildl Res 39:279-289. https://doi.org/10.1071/WR11166

Cooke BD, McPhee S, Hart Q (2008) Rabbits: a threat to conservation and natural resource management: how to assess a rabbit problem and take action. Bureau of Rural Sciences: Canberra, ACT. https://pestsmart.org.au/wp-content/uploads/2010/03/BRS_ Rabbit_Booklet_lr.pdf

Courchamp F, Langlais M, Sugihara G (1999) Control of rabbits to protect island birds from cat predation. Biol Conserv 89:219-225. https://doi.org/10.1016/S0006-3207(98)00131-1

Courchamp F, Langlais M, Sugihara G (2001) Rabbits killing birds: modelling the hyperpredation process. J Anim Ecol 69:154-164. https://doi.org/10.1046/j.1365-2656.2000.00383.x

Crowley SL, Hinchliffe S, McDonald RA (2017) Conflict in invasive species management. Front Ecol Environ 15:133-141. https://doi. org/10.1002/fee.1471

Da Silva AG, Kolokotronis SO, Wharton D (2010) Modeling the eradication of invasive mammals using the sterile male technique. Biol Invasions 12:751-759. https://doi.org/10.1007/ s10530-009-9477-5

Dalland M, Carter S (1998) The evaluation of a prehistoric mound damaged by rabbit burrowing at Maryton Law, Angus. Tayside Fife Archaeological Journal 4:20-30

Daly JC (1980) Age, sex and season: factors which determine the trap response of the European wild rabbit, Oryctolagus cuniculus. Wildl Res 7:421-432

Daniels TJ, Bekoff M (1989) Feralization: the making of wild domestic animals. Behav Process 19:79-94. https://doi.org/10.1016/03766357(89)90032-6

Delibes-Mateos M, Delibes M, Ferreras P, Villafuerte R (2008a) Key role of European rabbits in the conservation of the Western Mediterranean basin hotspot. Conserv Biol 22:1106-1117. https://doi. org/10.1111/j.1523-1739.2008.00993.x

Delibes-Mateos M, Fernandez de Simon J, Villafuerte R, Ferreras P (2008b) Feeding responses of the red fox (Vulpes vulpes) to different wild rabbit (Oryctolagus cuniculus) densities: a regional approach. Eur J Wildl Res 54:71-78. https://doi.org/10.1007/ s10344-007-0111-5

Delibes-Mateos M, Farfán MA, Rouco C, Olivero J, Márquez AL, Fa JE, Vargas JM, Villafuerte R (2018) A large-scale assessment of European rabbit damage to agriculture in Spain. Pest Manag Sci 74:111-119. https://doi.org/10.1002/ps.4658

Díaz-Ruiz F, Caro J, Delibes-Mateos M, Arroyo B, Ferreras P (2016) Drivers of red fox (Vulpes vulpes) daily activity: prey availability, human disturbanceor habitat structure? J Zool 298:128-138

Díez Valle C, Sanchez-García C, Pérez JA, Bartolomé DJ, González V, Wheatley CJ, Alonso NE, Gaudiosov VR (2013) Behaviour activity of wild rabbit (Oryctolagus cuniculus) under semi-natural rearing systems: Establishing a seasonal pattern. World Rabbit Sci 21:263-270. https://doi.org/10.4995/wrs.2013.1332

Dodaro G, Battisti C, Campedelli T, Fanelli G, Monaco A (2019) Unsafe management of a zoological garden as a cause of introduction of an alien species into the wild: First documented case of feral naturalized population of Lama glama in Europe. Journal Nat Conserv 49:22-26. https://doi.org/10.1016/j.jnc.2019.02.006

Faliu L, Lignereux Y, Barrat J (1980) Identification des poils des mammiferes Pyreneens. Doñana, Acta Vert 1:125-212

Fernandez-de-Simon J, Díaz-Ruiz F, Rodríguez-de la Cruz M et al (2015) Can widespread generalist predators affect keystone prey? A case study with red foxes and European rabbits in their native range. Popul Ecol 57:591-599. https://doi.org/10.1007/s10144-015-0510-5

Ferreira C (2012) European rabbit research in the Iberian Peninsula: state of the art and future perspectives. Eur J Wildl Res 58:885-895. https://doi.org/10.1007/s10344-012-0664-9

Ferretti F, Pacini G, Belardi I, ten Cate B, Sensi M, Oliveira R, Rossa M, Burrini L, Lovari S (2021) Recolonizing wolves and opportunistic foxes: interference or facilitation? Biol J Linn Soc 132:196-210. https://doi.org/10.1093/biolinnean/blaa139

Flux JEC (2008) A review of competition between rabbits (Oryctolagus cuniculus) and hares (Lepus europaeus). In: Alves PC, Ferrand N, Hacklander K (eds) Lagomorph Biology. Evolution, Ecology and Conservation. Springer Editions, Berlin and Heidelberg, Germany. pp 241-249

Katona K, Bíró Z, Hahn I, Kertész M, Altbäcker V (2004) Competition between European hare and European rabbit in a lowland area, Hungary: a long-term ecological study in the period of rabbit extinction. Folia Zool 53:255-268

Lashley MA, Cove MV, Chitwood MC, Penido G, Gardner B, DePerno CS, Moorman CE (2018) Estimating wildlife activity curves: comparison of methods and sample size. Sci Rep 8:4173. https://doi.org/10.1038/s41598-018-22638-6

Lees AC, Bell DJ (2008) A conservation paradox for the 21st century: the European wild rabbit Oryctolagus cuniculus, an invasive alien and an endangered native species. Mammal Rev 38:304-320. https://doi.org/10.1111/j.1365-2907.2008.00116.x

Linkie M, Ridout MS (2011) Assessing tiger-prey interactions in Sumatran rainforests. J Zool 284:224-229. https://doi.org/10. 1111/j.1469-7998.2011.00801.x

Meredith A, Brigitte L (2014) BSAVA Manual of Rabbit Medicine. BSAVA. ISBN: 978-1-905319-49-7

Meredith M, Ridout M (2018) Overview of the overlap package. https:// cran.r-project.org/web/packages/overlap/vignettes/overlap.pdf

Micol T, Jouventin P (1995) Restoration of Amsterdam Island, South Indian Ocean, following control of feral cattle. Biol Conserv 73:199-206. https://doi.org/10.1016/0006-3207(94)00109-4

Monterroso P, Alves PC, Ferreras P (2014) Plasticity in circadian activity patterns of mesocarnivores in southwestern Europe: implications for species coexistence. Behav Ecol Sociobiol 68:14031417. https://doi.org/10.1007/s00265-014-1748-1

Mori E (2010) La fauna alloctona nella Selva di Paliano (Frosinone): origine delle popolazioni, status attuale e ipotesi per la prevenzione degli impatti. Dissertation, University of Rome "La Sapienza"

Mori E, Amerini R, Mazza G, Bertolino S, Battiston R, Sforzi A, Menchetti M (2016) Alien shades of grey: new occurrences and relevant spread of Sciurus carolinensis in Italy. Eur J Ecol 2:13-20. https://doi.org/10.1515/eje-2016-0002

Mori E, Bagnato S, Serroni P, Sangiuliano A, Rotondaro F, Marchianò V, Cascini V, Poerio L, Ferretti F (2020) Spatiotemporal mechanisms of coexistence in an European mammal community in a protected area of southern Italy. J Zool 310:232-245

Nimmo DG, Miller K (2007) Ecological and human dimensions of management of feral horses in Australia: a review. Wildlife Res 34:408-417. https://doi.org/10.1071/WR06102 
Norbury G (2001) Conserving dryland lizards by reducing predatormediated apparent competition and direct competition with introduced rabbits. J Appl Ecol 38:1350-1361. https://doi.org/ 10.1046/j.0021-8901.2001.00685.x

Oberski D (2014) lavaan.survey: An R package for complex survey analysis of structural equation models. J Stat Softw 57:1-27. https://www.jstatsoft.org/v057/i01

Olivas I, Rodriguez-Latorre A, Estellés F, Calvet S, Villagrá A (2013) Assessment of activity patterns of growing rabbits in a flux-controlled chamber. World Rabbit Science 21:107-110. https://doi. org/10.4995/wrs.2013.1187

Papadopoulos E, Komnenou A, Thomas A, Ioannidou E, Colella V, Otranto D (2017) Spreading of Thelazia callipaeda in Greece. Transbound Emerging Dis 65:248-252. https://doi.org/10.1111/ tbed.12626

Pech RP, Sinclair ARE, Newsome AE, Catling PC (1992) Limits to predator regulation of rabbits in Australia: evidence from predator-removal experiments. Oecologia 89:102-112. https://doi.org/ 10.1007/BF00319021

Pimentel D, McNair S, Janecka J, Wightman J, Simmonds C, O'Connell C, Wong E, Russel L, Zern J, Aquino T, Tsomondo T (2001) Economic and environmental threats of alien plant, animal, and microbe invasions. Agr Ecosyst Environ 84:1-20. https://doi. org/10.1016/S0167-8809(00)00178-X

QGIS Development Team (2019) QGIS Geographic Information System. Open Source Geospatial Foundation Project. http://qgis. osgeo.org. Accessed on 01.06.2020.

R Core Team (2019) R: A language and environment for statistical computing. R Foundation for Statistical Computing, Vienna, Austria. https://www.R-project.org/

Randi E (2007) Detecting hybridization between wild species and their domesticated relatives. Mol Ecol 17:285-293. https://doi.org/10. 1111/j.1365-294X.2007.03417.x

Retfalvi L (1970) Food of nesting bald eagle on San Juan Island, Washington. The Condor 72:358-361

Revelle W (2019) psych: procedures for personality and psychological research. $\mathrm{R}$ package version $1.9 .12 \mathrm{http} / / /$ personality-project.org/r, https://personality-project.org/r/psych-manual.pdf

Reynolds JC, Aebischer NJ (1991) Comparison and quantification of carnivore diet by faecal analysis: a critique, with recommendations, based on a study of the fox Vulpes vulpes. Mammal Rev 21:97-122. https://doi.org/10.1111/j.1365-2907.1991.tb00113.x

Scapin P, Ulbano M, Ruggiero C, Balduzzi A, Marsan A, Ferrari N, Bertolino S (2019) Surgical sterilization of male and female grey squirrels (Sciurus carolinensis) of an urban population introduced in Italy. J Vet Med Sci 18:0319. https://doi.org/10.1292/ jvms.18-0319

Sogliani D, Mori E (2019) “The Fox and the Cat": sometimes they do not agree. Mammal Biol 95:150-154. https://doi.org/10.1016/j. mambio.2018.07.003
Sol Hart P, Larson BMH (2014) Communicating about invasive species: how "driver" and "passenger" models influence public willingness to take action. Conserv Lett 7:545-555. https://doi.org/ 10.1111/conl.12109

Suselbeek L, Emsens WJ, Hirsch BT, Kays R, Rowcliffe JM, ZamoraGutierrez V, Jansen PA (2014) Food acquisition and predator avoidance in a Neotropical rodent. Anim Behav 88:41-48. https:// doi.org/10.1016/j.anbehav.2013.11.012

Tavakol M, Dennick R (2011) Making sense of Cronbach's alpha. Int J Med Edu 2:53-55. https://doi.org/10.5116/ijme.4dfb.8dfd

Teerink BJ (1991) Hair of West-European mammals. Cambridge University Press, Cambridge, UK

Trouwborst A (2014) Exploring the legal status of wolf-dog hybrids and other dubious animals: International and EU law and the wildlife conservation problem of hybridization with domestic and alien species. RECIEL 23:111-124. https://doi.org/10.1111/reel.12052

Vaske JJ (2008) Survey research and analysis: applications in parks. State College, Pennsylvania Venture Publishing Inc, Recreation and Human dimensions

Vastrade FM (1986) The social behaviour of free-ranging domestic rabbits (Oryctolagus cuniculus L.). Appl Anim Behav Sci $16: 165-177$

Vastrade FM (1987) Spacing behaviour of free-ranging domestic rabbits, Oryctolagus cuniculus L. Appl Anim Behav Sci 18:185-195

Velarde R, Cavadini P, Neimanis A, Cabezòn O, Chiari M, Gaffuri A, Lavìn S, Grilli G, Gavier-Widén D, Lavazza A, Capucci L (2017) Spillover Events of Infection of Brown Hares (Lepus europaeus) with Rabbit Haemorrhagic Disease Type 2 Virus (RHDV2) Caused sporadic cases of an European brown hare syndrome-like disease in Italy and Spain. Transbound Emerg Dis 64:1750-1761. https://doi.org/10.1111/tbed.12562

Villafuerte R, Delibes-Mateos M (2019) Oryctolagus cuniculus. The IUCN Red List of Threatened Species 2019:e.T41291A45189779

Watson JS (1961) Feral rabbit populations on Pacific Islands. Pac Sci 15:591-593. http://hdl.handle.net/10125/12562

World Weather Online. https://www.worldweatheronline.com/

Young JK, Olson KA, Reading RP, Amgalanbaatar S, Berger J (2011) Is wildlife going to the dogs? Impacts of feral and free-roaming dogs on wildlife populations. Bioscience 61:125-132. https://doi. org/10.1525/bio.2011.61.2.7

Zenger KR, Richardson BJ, Vachot-Griffin AM (2003) A rapid population expansion retains genetic diversity within European rabbits in Australia. Molec Ecol 12:789-794. https://doi.org/10.1046/j. 1365-294X.2003.01759.x

Publisher's Note Springer Nature remains neutral with regard to jurisdictional claims in published maps and institutional affiliations. 